\title{
Nonlinear stress-strain behavior of corrosion-damaged reinforcing bars including inelastic buckling
}

\author{
Mingqiang Lin ${ }^{1,}$, Fengjuan Dai ${ }^{2, b}$ and Jiatao $\mathrm{Li}^{3, \mathrm{c}}$ \\ ${ }^{1}$ School of Civil Engineering and Architecture, University of Jinan, Jinan, China \\ ${ }^{2}$ School of Civil Engineering,Shandong Jiaotong University ,Jinan, China \\ ${ }^{3}$ Shandong construction Engineering (group)co.Itd ,Jinan, China \\ amqqmI@163.com, bdaifengjuan@163.com, ${ }^{\mathrm{c}} 31932600 @ q q . c o m$
}

Keywords: corroded, pits, capacity, nonlinear buckling.

Abstract. Corrosion of reinforcement is the most common type of deterioration of reinforced concrete structures and bridges. Serious degradation of the mechanical properties of reinforcing bars is because of corrosion. Pitting corrosion is the main form of corrosion. The nonlinear stress-strain behavior of corroded reinforcing bars has been investigated by finite element theory. The effect of different corrosion levels on the compression behavior of bars with different slenderness ratios is presented. It was found that the softening of compressive stress takes place due to the geometrical nonlinearity associated with the lateral deformation of the compressed bars, especially after the absolute strain exceeds the yielding strain. Degradation of longitudinal reinforcement bearing capacity which was caused by pit sizes, pit locations, pit types, and slenderness ratios was analyzed. The results of this study show that slenderness ratio and pit depth significantly affect changes the buckling collapse mechanism of the bars in compression. Moreover, a unique relationship between pit size and the carrying capacity of reinforcing bars including the effect of buckling is established through various parametric analyses.

\section{Introduction}

Corrosion of steel in concrete and actual mechanism of reinforced concrete structures under corrosive environment in the case of steel corrosion test results showed that corrosion of steel in concrete often from local pits began to evolve and grow, these pits will result in the presence of steel under the stress state of stress concentration around the pits, resulting in degradation of mechanical properties of steel. Corrosion pits is causing the degradation of the mechanical properties of reinforced main reason for its depth the degradation of the mechanical properties of steel has an important affected.

Literature [1-2] have studied that the tensile mechanical properties of reinforcing bars were impacted by pits. Sensitivity analyses of the effects of the geometric parameters (such as the width, depth, location of the pit, rebar diameter, etc) of the corrosion pit on the mechanical properties of the rusty rebar were performed. Stochastic finite element method was applied to study the stress distribution of the rusty rebar. It is discovered that the maximum depth of the corrosion pit is the crucial factor for the mechanical property of the rusty rebar with the same diameter. For the rebar with different diameters, relative corrosion depth (ratio between the pit depth and the diameter of the rusty rebar) could be applied to describe the corrosion state of the rusty rebar. According to the mechanical analyses of the rusty rebar with different corrosion depth, relation-ship between the yield load of the rusty rebar and its relative corrosion depth is built up. Taken the maximum corrosion pit depth as the stochastic variable, the distribution of the maximum stress in the rusty rebar is then achieved.

There has been a lot of research on buckling behavior of uncorroded reinforcements. Mario propose a method predicted buckling of reinforcements according to 36 aspect ratio $\mathrm{L} / \mathrm{D}=2.5 \sim 8.0$ reinforced buckling tests ${ }^{[3]}$.Using the COM3, Rajesh has studied the buckling behavior of the change of aspect ratio with law with contrasting the buckling behavior of reinforced control 18 aspect ratio $\mathrm{L} / \mathrm{D}=$ 5.5 15.0 reinforced test results ${ }^{[4]}$. Sung Jin has carried out the behavior of reinforced buckling according to the 162 aspect ratio $\mathrm{L} / \mathrm{D}=4 \sim 12$ reinforced buckling tests ${ }^{[5]}$.In the seismic design and 
assessment of reinforced concrete structures in earthquake zones buckling of longitudinal reinforcement in plastic hinge regions is an important limit state that needs to be considered. If the structure is located in an environmentally aggressive area, it is also subject to material deterioration over its service life. Corrosion of reinforcement is the most common type of deterioration of reinforced concrete (RC) structures and bridges. The nonlinear stress-strain behavior of corroded reinforcing bars has been investigated by Mohammad by extensive experimental testing ${ }^{[6]}$. The effect of different corrosion levels on the compression behavior of bars with different slenderness ratios is presented. He showed that a corrosion level above $15 \%$ mass loss significantly affects the ductility and plastic deformation of reinforcement in tension and that corrosion changes the buckling collapse mechanism of the bars in compression. Its results also show that the distribution of corrosion pits along the length of corroded bars is the most important parameter affecting the stress-strain response in compression. Furthermore, a constitutive material model to predict the post-yield buckling behavior of high-strength steel without a yield plateau is also developed.

Therefore, in this paper, the mechanical properties of corroded reinforcement caused by pits has important theoretical significance and practical value, but the current research work in this area is still less carried purpose of this paper is to study theoretically the size of the rebar corrosion pit mechanics performance of the law, analyzing steel stress corrosion pits caused by changes in the distribution of corroded reinforced concrete mechanical properties test and numerical analysis to establish a theoretical foundation.

\section{Analytical simulation of bar buckling}

In this paper, steel bearing strengths of bars with the pit are analyzed by finite element. Reinforcing bars obtained using solid model. SOLID45 is solid elements. The diameter of bar is $18 \mathrm{~mm}$. The lengths were used according to the diameter of the multiple. Cylinder simulates steels, stainless steel surface rust pit based on the shape of the substrate through a reinforced body with idealized pit Boolean subtraction to get done, then the entity model mesh. The three-line isotropic steel reinforced plastic model, elastic modulus of $2.0 * 10^{5} \mathrm{MPa}$, elastic strain of 0.002 , the yield strain of 0.02 , yield stress of $400 \mathrm{MPa}$, ultimate strain of 0.15 based on three-dimensional modeling, the reinforced side constraints, in another section of the load applied to the displacement, the load is divided into several sub-steps, which can be reinforced load - deformation curve.

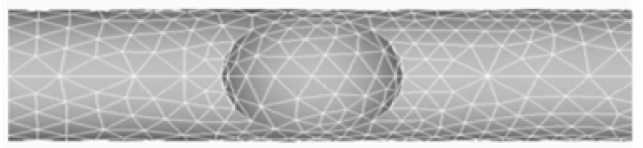

Fig.1 The finite element

\section{Analysis of results and discussions}

\section{shape of rust pits}

The chloride ion penetration reinforcement rust pits macroscopic shape feature more obvious by the geometric simplification, roughly divided into: dark oval, spherical, oblong and groove-shaped four shapes. Rust deep oval pit where deep and narrow, fewer, smaller in size, while the other three shapes showed rust pits are shaped opening width is larger, so the shape of the rust pits four different calculation and analysis was out: Rust pit type and location of steel buckling patterns have a certain influence on the ultimate load is also reduced impact. Pit depth is the most important factor affecting rust pit size of

Literature [1] has studied the rust pits on the steel tensile performance. The results showed rust pit depth is affecting the main reason for its tensile properties. Based on the $18 \mathrm{~mm}$ diameter rebar, steel intermediate rust pits with different diameters calculated capacity as shown in Figure2. Regression calculation results, obtained with stainless steel bearing capacity pit depth relationship, for equation (1). Figure 2 shows, as the increase of the diameter rust pits, steel capacity gradually reduce a 
quadratic curve. Derivative of the formula derived by Equation (2), can be derived as the diameter increases rust pits, the second order derivative of the curve into a straight line, carrying capacity is more and more decreasing trend.

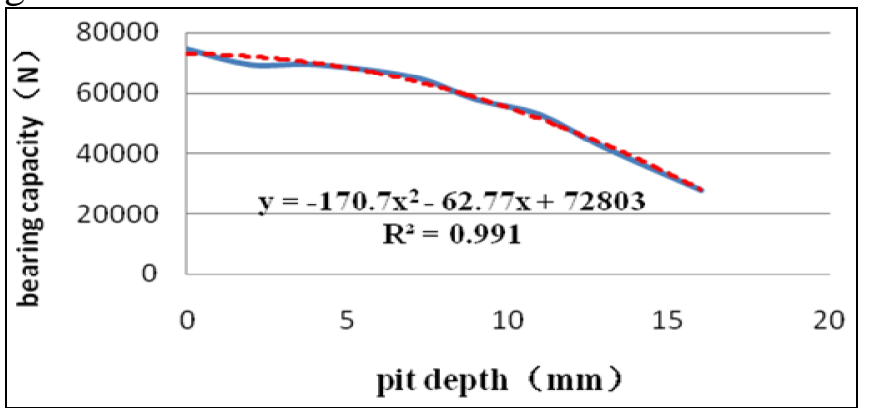

Fig.2 The relationship of pit depths and bearing capacity of bars

$$
\begin{gathered}
y=-170.72 x^{2}-62.771 x+72803 \\
y=-341.44 x-62.771
\end{gathered}
$$

\section{Location of rust pits}

Erosion caused by the chlorine ion distribution of corroded pits are random, and rust pit different positions at different cross-section makes the steel net area is reduced, affecting the bearing strength. In this paper, Fig 4 (b) shows the location of different pit diameter stainless steel of $18 \mathrm{~mm}$ calculated results. Rust pit in the middle position on the steel reinforcement buckling load forces the greatest impact, with the rust pit position shift effect gradually reduced. When the rust pits at position 1, 2 and 3 , the intermediate reinforcement buckling is based, and when the stainless steel end portion near the pit (position 4), reinforced buckling morphological changes, reinforcement bars form a buckling point, rust pit position also produced local buckling point, so its displacement - load curve and the curve of the position 3 descending apparent steel ductility decreased significantly.

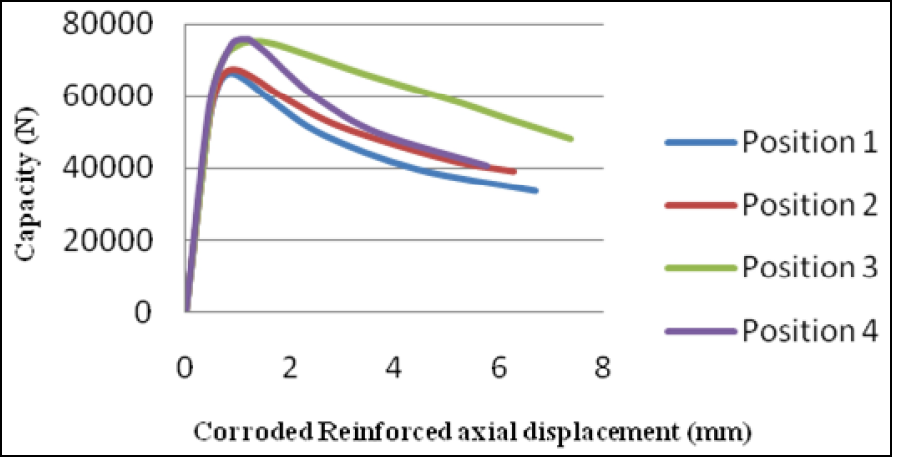

(a) the relationships of different locations of pits and the capacity

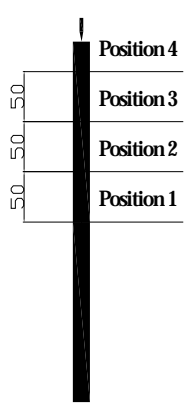

(b) pit positions

\section{Slenderness ratios}

Fig.3 The relationship of pits location and bearing capacity of reinforcing bars

Slenderness ratio is an important factor on affecting buckling. Partial reinforcement corrosion makes the slenderness ratio increase. Local stress concentration makes in performance degradation. The same corrosion rate and different slenderness ratio of steel capacity are shown in Fig.4. Calculation results show that with the aspect ratio changes, buckling curve corroded reinforcement morphology changed significantly, can be broadly divided into the following four types:The first category curve $(\mathrm{L} / \mathrm{D} \leq 10)$ of these curves significantly enhanced segment, the performance characteristics of a typical intensity of destruction, with the corresponding tensile curve similar shape. Such reinforcement aspect ratio is very small, corresponding to the column stirrups are not encrypted area hoop rust off the case. Type II curves $(10<\mathrm{L} / \mathrm{D} \leq 20)$ of these limit load curve near the steel yield the corresponding $\mathrm{P}_{\mathrm{u}}$ load. Before reaching the $\mathrm{Pu}$ substantially linear curve, the curve was linear up $\mathrm{P}_{\mathrm{u}}$ decreased slowly after the no enhancement paragraphs. reinforcement aspect ratio is small, corresponding to the column hoop hoops non-encrypted area is not the case of the rust off, The third category curve $(20<\mathrm{L} / \mathrm{D} \leq 49)$ of these curves is usually significantly lower than the ultimate load $\mathrm{P}_{\mathrm{u}}$ total cross section of steel yielding the corresponding loads. Loads reach $\mathrm{P}_{\mathrm{u}}$ before the curve shows 
obvious nonlinear characteristics reach $\mathrm{P}_{\mathrm{u}}$ capacity plummeted after the test pieces. reinforced larger aspect ratio, corresponding to the column stirrup rust off situation. The fourth category curves (L / D > 49) Such curves ultimate load $P_{u}$ total cross section of the test piece much lower yield load, load up before $\mathrm{P}_{\mathrm{u}}$ showed significant nonlinear curve, reaching $\mathrm{P}_{\mathrm{u}}$ reduced capacity after the test pieces trends more gentle. reinforced large aspect ratio, corresponding to the column end stirrups occur multiple root rust off situation.

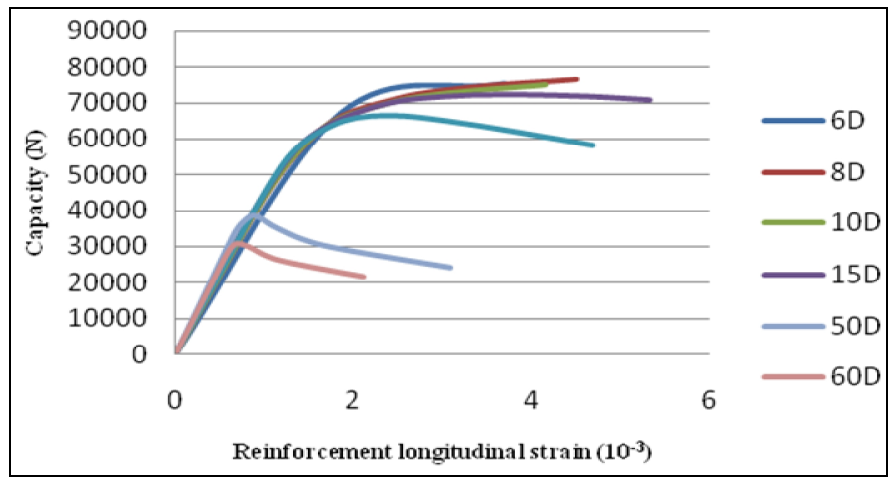

Fig.4 The relationship of strain and bearing capacity of reinforcing bars

\section{Conclusions}

The effects of corrosion on the stress-strain behavior of reinforcing bars in compression have been studied. The key observations from this work can be summarized as follows: Analyses using finite elements with small size were conducted to predict the average behavior of reinforcing bars in compression accompanying geometrically large nonlinearity which is feasible. Slenderness ratio and pit depth significantly affect changes the buckling collapse mechanism of the bars in compression. Pit type and location have a certain influence on the ultimate load, steel buckling patterns is also impacted. Based on the results, obtained with stainless steel ultimate pit depth capacity formula for the calculation of corroded reinforced concrete to provide a theoretical foundation and basis of calculations.

\section{Acknowledgements}

This work was financially supported by science and technology program of Shandong province institution (J15LG54).

\section{References}

[1] Fan Yingfang、Zhang Yingzi、Hu Zhiqiang:Journal of building materials:2006,vol(9) nov(1). In Chinese.

[2] Fan Yingfang,Zhou Jing. Journal of building materials:2003,vol(6) nov (3). In Chinese.

[3] Mario E R, Juan C B, Jaime V. Cyclic stress- strain behavior of reinforcing steel including effect of buckling [ J] . Journal of Structural Engineering: ASCE, 1999, 125(6): 605.

[4] Rajesh P D, Koichi M. Modeling for post yields buckling of reinforcement [J]. Journal of Structural Engineering: ASCE, 2002, 128

[5] Sungjin B, Alexa M, Oguzhan B. Inelastic buckling of reinforcing bars [J]. Journal of Structural Engineering: ASCE, 2005,131( 2) : 314.

[6] Mohammad M. Kashani, Adam J. Crewe, Nicholas A. Alexander. Nonlinear stress-strain behavior of corrosion-damaged reinforcing bars including inelastic buckling [J]. Engineering Structures 48 (2013) 417-429

[7] JIANG Fengchang, Zhu Cimian, Xue Jiansheng, Zhao Yinghao.Non-linear Analysis of Buckling Carrying Capacity for Corroded Reinforcing Bars Based on ANSYS[J]. JOURNAL OF TONGJI UNIVERSITY (NATURAL SCIENCE) Aug. 20081045-1049.In Chinese. 